\title{
O Portfólio e a Avaliação no Ensino Superior
}

\author{
JUREMA NOGUEIRA MENDES RANGEL \\ Mestre em Educação, especialista em psicopedagogia. \\ Docente da Universidade Estácio de Sá \\ jurema@ajato.com.br
}

\begin{abstract}
Resumo
O presente trabalho tem por objetivo refletir sobre o sentido da avaliação, a partir de uma experiência sobre o uso de portfólio no ensino superior como uma alternativa de avaliação do processo de aprendizagem. Esta prática avaliativa deu-se junto às turmas de $1^{\circ}$ Período de Odontologia, matriculadas na disciplina de metodologia científica, na Universidade Estácio de Sá (Rio de Janeiro), entre 2001 e 2003, envolvendo 150 alunos, em encontros semanais de $4 \mathrm{~h} / \mathrm{a}$, totalizando uma carga horária de $80 \mathrm{~h} /$ a no semestre letivo. Os resultados demonstram a apropriação das múltiplas linguagens, além da científica, própria da disciplina; a adequação da prática de leitura, escrita e pesquisa envolvendo estratégias de revisão e reflexão sobre as atividades; o constante e permanente diálogo entre o professor e aluno, aluno/aluno; a dificuldade de o estudante elaborar o portfólio demonstrativo, nitidamente reflexivo; ênfase no processo de aprender e não no resultado. Conclui-se que alguns entraves precisam ser vencidos: a mudança da concepção de avaliação como quantificação que permeia o pensamento dos alunos e professores e a inserção de outras disciplinas que possam compartilhar desta prática para a assunção de um novo lugar para a avaliação, no contexto acadêmico.
\end{abstract}

Palavras-chave: avaliação, universidade, portfólio.

\section{Resúmen}

El objectivo del presente trabajo es reflexionar sobre el sentido de la evaluación, a partir de una experiencia sobre el uso del portfolio en la enseñanza superior, como una alternativa de evaluación del proceso de aprendizado. Este método de evaluación se practicó em clases del $1^{\circ}$. Periodo de Odontología, matriculadas em la disciplina de metodología científica, en el Universidade Estácio Sá (Rio de Janeiro), entre 2001 y 2003, involucrando 150 estudiantes, durante encuentros semanales de $4 \mathrm{~h} / \mathrm{a}$, com uma carga horaria total de $80 \mathrm{~h} /$ a por semestre lectivo. Los resultados demuestran la asimilación de los múltiples lenguajes, además del científico, propio de la disciplina; la adecuación de la práctica de la lectura, la escritura e investigación que involucran estrategias de revisión y reflexión sobre las actividades; el constante y permanente diálogo entre el profesor y alumno, alumno/alumno; la dificultad del estudiante para elaborar el portfolio demostrativo, claramente reflexivo; el énfasis en el proceso de aprendizado y no en el resultado. Se concluye que algunos obstáculos necesitan ser vencidos: el cambio del concepto de evaluación como cuantificación que está en el modo de pensar de los estudiantes y profesores y la inclusión de otras disciplinas que puedan usar esta práctica para asumir un nuevo lugar para la evaluación, en el contexto académico.

Palabras-clave: evaluación, universidad, portfolio.

Estudos em Avaliação Educacional, n. 28, jul-dez/2003 


\begin{abstract}
The purpose of this study is to discuss the meaning of evaluation based on an experience involving the use of portfolio at college level as an alternative to evaluation of the learning process. This was conducted with $1^{\text {st }}$ semester students in Dentistry, attending Scientific Methodology classes at the Universidade Estácio de Sá (Rio de Janeiro), between 2001 and 2003. It involved 150 students, in 4-hour weekly meetings, amounting to a total workload of $80 \mathrm{~h}$ in the school semester. The results demonstrated the adequacy of using multiple languages - besides the subject's scientific one - like reading, writing and research involving revision and reflection strategies about the activities; the constant and permanent dialogue between teacher and student, student and student; the student's difficulty to prepare the clearly reflective portfolio; emphasis on the learning process and not on the result. It was found that some problems need to be overcome: it is necessary to change the concept of evaluation as quantification which permeates students' and teachers' thinking and to include other subjects that can share this practice so that evaluation can start playing a new role in the academic context.
\end{abstract}

Key words: evaluation, university, portfolio. 


\section{INTRODUÇÃO}

O presente trabalho tem por objetivo refletir sobre o sentido da avaliação, a partir de uma experiência sobre o uso de portfólio, no ensino superior, como uma alternativa para a avaliação do processo de aprendizagem do estudante. $\mathrm{O}$ interesse sobre esta prática ancora-se na trajetória como docente em diferentes níveis de escolaridade, atrelada à formação psicopedagógica, adquirida no curso de especialização em Psicopedagogia em Educação, realizado na Universidade Estácio de Sá, em 1995. A partir dos aportes teóricos da psicopedagogia sobre o estudo dos processos de aprendizagem e suas dificuldades (Bossa, 2000), os constantes questionamentos sobre os procedimentos avaliativos classificatórios, historicamente constituídos e marcadamente excludentes, que acompanharam o cotidiano da sala de aula, durante muito tempo, começaram a ser repensados. A preocupação com o ensinar, com a figura do professor e a sua didática, tão fortemente enfatizados no tempo da graduação, muitos anos antes, foi sofrendo mudanças significativas, com a inserção da compreensão do processo de aprender do aluno, condicionado por vários fatores, incluindo, aí, o professor. A avaliação passou a situar-se "[...] como uma análise do processo construtivo do aluno e do professor" (Fernández, 2001, p. 39).

Ciente dos limites impostos pela instituição que delineia, no seu regimento, as formas de avaliar o aluno, mas não impedem a inserção de novas práticas que visem ao desenvolvimento da autonomia do estudante, introduziu-se, a partir de 2001, na disciplina de metodologia científica, oferecida às turmas do primeiro período do Curso de Odontologia da Universidade Estácio de Sá, a construção do portfólio pelo aluno, não apenas como mais um instrumento de avaliação, mas como eixo norteador de um modo de aprender a aprender que permitisse ao estudante investigar o seu processo de construção do conhecimento.

Tentando corresponder a um dos anseios do projeto pedagógico do Curso de Odontologia (Universidade Estácio de Sá, 2002), que preconiza a formação de um profissional generalista, crítico, capaz de reavaliar o seu potencial de desempenho e de ajustar-se, com competência, às demandas geradas pelo avanço tecnológico do mundo globalizado, acredita-se que o uso do portfólio, no ensino superior, é um dos recursos possíveis para colocar o aluno como responsável pelo seu processo de aprendizagem, favorecendo a postura reflexiva que envolva o reconhecer-se pensante e, ao mesmo tempo, um sujeito desejante (Fernández, 2001). 
Assim, este trabalho pretende, inicialmente, apontar as bases teóricas que fundamentam a proposta de avaliação com o portfólio, para, em seguida, apresentar o desenvolvimento da construção do portfólio com os alunos de odontologia e, finalmente, tecer algumas considerações acerca da implementação do seu uso, na prática avaliativa.

\section{A AVALIAÇÃO: O PORTFÓlIO COMO ALTERNATIVA}

A avaliação é um tema que perpassa as discussões sobre a educação em qualquer nível de ensino. A literatura disponível sobre o tema é vasta e, nela, os estudos de Esteban (1999, 2001), Hadji (2001) e Perrenoud (1999, 1999a) desvendam o que está em jogo quando se avalia, alertando ser o momento da avaliação um dos maiores entraves para o sucesso do estudante, na instituição de ensino.

Esteban (1999, 2001), embora discuta a avaliação no ensino fundamental, traz colaborações importantes ao apontá-la como integrante de um processo mais amplo sobre o fracasso escolar, intrinsecamente relacionada com a inclusão e exclusão de grupos sociais a conhecimentos socialmente valorizados. A autora desloca a avaliação centrada nas impossibilidades dos alunos, tão enfatizada pelos docentes, para colocar em relevo os fatores institucionais que fortalecem o insucesso dos alunos, nas escolas.

Os estudos de Hadji (2001) complementam esta discussão ao abordar a cultura da avaliação formativa, introduzida há 30 anos atrás, como uma forma concreta de sair do imobilismo de procedimentos verificativos para uma vivência criadora de acompanhamento da progressão dos alunos. Defende a avaliação como um elemento a serviço das aprendizagens, possibilitando compreender a situação do aluno, equacionando o seu desempenho, alimentado por indicações dadas pelo docente que façam o aluno prosseguir e não recrudescer. Esta idéia é corroborada por Perrenoud (1999), ao mencionar a complexidade que o tema avaliação abrange, enfatizando que mudar a avaliação significa, provavelmente, mudar a escola, pois implica uma ruptura com as estratégias habituais, já estabilizadas e a incorporação de uma relação pedagógica cooperativa.

A avaliação arraigada em abordagens teóricas que colocam o resultado da produção do aluno em primeiro lugar, restringindo-se à verificação pontual de determinados conteúdos, normalmente vinculada a fases terminais dos períodos letivos, cede lugar, hoje, a um debate que 
contextualiza a avaliação no âmbito epistemológico. Este movimento representa deslocar o foco do aluno para um panorama que engloba também o professor, o currículo, os sistemas educacionais, enfim, todos os elementos envolvidos com o ensinar e o aprender.

Assim, sem esquecer que muitas instituições ainda utilizam mecanismos excludentes, porque selecionam, hierarquizam e discriminam os que sabem daqueles que não sabem, como diz Esteban $(1999,2001)$, defende-se, aqui, uma prática avaliativa que atenda não ao depois $d a$, mas ao processo da aprendizagem. A avaliação não deve servir para julgar ou para provar quais são os melhores alunos ou quem aprendeu o quê. A avaliação deve estar a serviço da ação em processo (Schön, 2000), alimentando e reorientando o percurso da aprendizagem do estudante. Neste caso, não há $a$ avaliação, mas um conjunto de avaliações que sinalizam o caminhar do aluno, no seu processo de aprender.

Fernández, ao discutir a relação entre ensinantes e aprendentes, revela que a avaliação sempre comporta um terreno frustrante, independentemente da técnica utilizada, porque inscreve um efeito desqualificante para as subjetividades em jogo. Logo: “O avaliar deve ser um acompanhar, um analisar, um pensar, um atender. Um momento de descanso para pensar no que viemos realizando, em como nos sentimos e o que estivemos fazendo" (Fernández, 2001, p. 39).

Portanto, mais do que saber que existem várias concepções de avaliação, é fundamental refletir sobre o sentido da avaliação, na instituição de ensino. É com este intento que alguns aspectos são sistematizados a seguir, para perceber-se a relevância de uma avaliação centrada na emancipação do sujeito.

Hadji (2001) destaca três momentos da avaliação em relação à ação de formação:

- a avaliação anterior à ação de formação, que objetiva um ajuste recíproco entre aluno e o currículo, ou seja, há uma preocupação em adequar a proposta de ensino à clientela escolar. É a chamada avaliação prognóstica;

- a avaliação pós-ação de formação, que significa a avaliação cumulativa, cuja intenção é verificar as aquisições ao final de um período. Utiliza recursos como a avaliação sócio-afetiva (atitude, valores, interesse, iniciativa), a autoavaliação, a participação (entrega de material, tarefas, etc.), trabalho em grupo (gestão coletiva de produção do conhecimento);

- a avaliação no centro da ação de formação, conhecida como avaliação formativa, que pretende atuar como reguladora da atividade do ensino. Está atenta ao ritmo, ao método de ensino, às estratégias, etc. Centra-se nas informações mais precisas, de ordem qualitativa, sobre os processos de aprendizagem do aluno. 
Na prática, porém, sabe-se que estas ações não são isoladas, mas misturam-se, às vezes de forma desequilibrada, para atender às intenções educativas da instituição. Em alguns momentos, a avaliação tende mais a um tipo de ação do que outro, fazendo com que o sentido da avaliação se aproxime de práticas de silenciamento, que conferem vozes a alguns apenas, fazendo das relações dialógicas, relações dissonantes, hierarquicamente definidas em que não há espaço para indagações e expressão de pensamentos (Eesteban, 1999). Ou seja, quer se chamar a atenção para o caráter da informatividade que a avaliação deve conter e por isto está intrinsecamente relacionada com as intenções inscritas no projeto pedagógico de cada instituição, pois "a partir do momento em que se informa, ela é formativa, quer seja instrumentalizada ou não, acidental ou deliberada, quantitativa ou qualitativa (Hadji, 2001, p. 20).

A avaliação, proposta pelos autores referidos, baseia-se numa prática avaliativa que afeta tanto o aluno quanto o professor, o que significa alterar o reconhecimento do professor como o único responsável sobre o que o aluno consegue ou não produzir para uma dimensão que envolve regulações coletivas e individualizadas, com vistas a otimizar os itinerários de produção do conhecimento por parte do estudante. A avaliação, no centro do processo de formação, possibilita, ao aluno, a tomada de consciência das suas dificuldades e avanços, durante o processo de aprendizagem. Ao professor, esta abordagem favorece a flexibilização necessária para a modificação de sua ação pedagógica em função de aquisições efetivas dos alunos. Como aponta Allal apud Hadji (2001):

À coleta de informações, referente aos progressos realizados e às dificuldades de aprendizagem encontradas pelo aluno, acrescenta-se uma interpretação dessas informações, com vistas a operar um diagnóstico das eventuais dificuldades, tudo isso levando a uma adaptação das atividades de ensino-aprendizagem - coleta de informações/diagnóstico individualizado/ajuste de ação, assim se apresenta a seqüência formativa. (p.21)

Esta abordagem, durante o processo de aprendizagem, inscreve a avaliação formativa na lógica da resolução de problemas, porque coloca, em cena, a especificidade de um ensino diferenciado. $\mathrm{Na}$ visão de Huberman apud Perrenoud (1999), a avaliação passa a concentrar-se na individualização das aprendizagens, na diferenciação das intervenções, nos meios pedagógicos, nas etapas e ritmos da aprendizagem e nos objetivos.

Portanto, as práticas avaliativas homogeneizadoras, que focalizam apenas a quantificação, as atitudes e tudo que o aluno adquire, perdem o seu lugar. O que se quer é promover uma avaliação ao longo do processo 150

Estudos em Avaliação Educacional, n. 28, jul-dez/2003 
de aprender, centrada no diálogo professor/ aluno, com vistas à emancipação do sujeito e conseqüentemente, uma revisão das relações de poder que orientam a dinâmica escolar (Esteban, 2001).

Neste caso, o portfólio abre esta oportunidade. Muito utilizado no ensino europeu e americano, a partir da década de 90, o portfólio recebe nomenclaturas diferentes, como, por exemplo, processofólio (Gardner, 2000) e dossier, na França (Alves, 2002). Independentemente do termo empregado, a sua concepção tem suas raízes no mundo das artes (o cinema, a fotografia, o design), como um suporte eficaz para uma amostra dos melhores trabalhos de um artista.

Para Shores e Grace (2001, p. 43): “O portfólio é definido como uma coleção de itens que revela, conforme o tempo passa, os diferentes aspectos do crescimento e do desenvolvimento de cada criança". Gardner (2000) diz que um portfólio padrão reúne os melhores trabalhos para algum tipo de competição ou exibição. O portfólio, então, não é apenas uma coletânea de trabalhos realizados pelo estudante, durante um período, mas, um documento que registra os melhores trabalhos, selecionados pelo aluno, para representarem a sua produção, num espaço de tempo.

A organização do material produzido pelo aluno em uma pasta "arquivo", ou como dizem Shores e Grace (2001), em um portfólio de aprendizagem, consiste na primeira etapa da proposta. O que se faz, neste momento, é a inclusão de anotações diárias, visitas, resumos, projetos, relatórios, desenhos, provas, testes, esquemas, fotos, reflexões, produções de colegas e outros. A partir da organização deste material, o aluno separa o que lhe é mais significativo, considerando as experiências vividas, seus interesses, enfim, escolhe o material mais representativo do seu percurso. Este material constitui, então, o portfólio ou portfólio demonstrativo (Shores; Grace, 2001), segunda etapa deste processo, que aponta os avanços ou mesmo a persistência de algumas dificuldades ainda não solucionadas. O portfólio reflete não apenas as produções relativas ao cognitivo, no seu sentido restrito, mas também os aspectos afetivos que perpassam a produção intelectual do sujeito.

Esta proposta, então, convida o estudante a retomar as suas produções, fontes primárias, com um certo distanciamento, pois, ao analisá-las, começa a perceber o seu compromisso com o aprender, a sua modalidade de aprendizagem, o seu envolvimento com os temas estudados. Além disso, é possível compará-las com os comentários dos colegas e do professor, testes e avaliações pontuais (fontes secundárias), que complementam a visão do caminho percorrido. Este contexto é bastante favorável à inclusão, na sala de aula, de uma prática que implique 
o conceito de zona de desenvolvimento proximal, introduzido por Vygotsky (1993), em que enfatiza a dependência da cooperação entre os sujeitos para o desenvolvimento das funções psicológicas superiores.

O que se percebe, com a implementação do uso do portfólio, é uma ruptura do modelo técnico e quantitativo de avaliação para um processo multidimensional, solidário e coletivo de ensino/aprendizagem. O conhecimento transita em várias direções e os colegas passam a ter um lugar significativo, visto que também oferecem feed-backs, trocas de opiniões. Está implícito, portanto, que cada portfólio é único, uma vez que é de exclusiva responsabilidade do aluno, mesmo que, em momentos demarcados, professor e aluno, os colegas entre si, conversem sobre as produções ocorridas, confirmando a idéia de que a avaliação demanda a interação, a troca e a negociação entre os sujeitos envolvidos com um determinado objeto (Hadji, 2001).

O que é fundamental não é o portfólio em si, mas o que o estudante aprendeu ao construí-lo a respeito da disciplina, do seu processo de aprender e de si mesmo. A prática reflexiva conduz o estudante a constantes indagações (Schön, 2000) e inscreve o ensino e a aprendizagem na perspectiva da transformação.

\section{O PORTFÓLIO: UMA PRÁTICA NA ODONTOLOGIA}

A experiência da avaliação utilizando o portfólio teve início com as turmas de $1^{\circ}$. Período de Odontologia da Universidade Estácio de Sá, em 2001, envolvendo 150 alunos até o segundo semestre de 2003, em encontros semanais de $4 \mathrm{~h} / \mathrm{a}$, totalizando uma carga horária de $80 \mathrm{~h} / \mathrm{a}$ no semestre letivo. Num primeiro momento, apresentou-se, por escrito, aos estudantes, a proposta do uso do portfólio, justificando sua inserção na disciplina de metodologia científica que, entre outros objetivos, pretende favorecer a reflexão sobre a redação científica, estratégias de estudo e de leitura e promover uma atitude favorável aos métodos e técnicas de estudo em geral e no mundo da odontologia, em particular, com vistas ao desenvolvimento de habilidades e competências próprias do profissional em odontologia. Procurou-se destacar que o portfólio auxiliaria o estudante a atingir estes objetivos, contribuindo também para a aproximação entre a teoria e a prática, a sistematização das atividades propostas, para a criatividade e a livre expressão e para o atendimento às dificuldades particulares de cada aluno. 
A inserção do portfólio no contrato pedagógico (Schön, 2000; Perrenoud, 1999a; Villas Boas, 2001), logo no início do semestre, firmou:

- O registro de aspectos considerados relevantes pelo aluno;

- A identificação dos resultados e, principalmente, do processo de produção das atividades;

- O uso das múltiplas linguagens, além da científica, própria da disciplina;

- A inclusão de qualquer material referente a qualquer disciplina ou mesmo outro material representativo de situações vividas fora da sala de aula, que complementasse as atividades destacadas no portfólio;

- O procedimento de leitura, escrita, pesquisa envolvendo estratégias de revisão e reflexão sobre as atividades;

- O diálogo constante e permanente entre o professor e aluno.

Neste contrato, foram estipuladas datas para a apresentação do portfólio de aprendizagem e portfólio demonstrativo, este no final do semestre letivo, analisado junto com cada aluno, buscando, de certa forma, resgatar ou reforçar as competências vislumbradas durante o processo de aprendizagem. As competências, conforme Perrenoud (1999a), referem-se a um conjunto de disposições e esquemas mobilizadores de conhecimentos, numa determinada situação e, neste caso, é fundamental que o aluno tenha a oportunidade de, junto com o professor, analisar as soluções encontradas para a resolução das atividades propostas, vividas durante o curso, agora apresentadas em forma de relatos, comentários e reflexões.

Estas "paradas" para troca entre colegas e entre professor/aluno formalizam as análises em produções textuais que atuam como balizas do processo cognitivo em andamento. Tornam-se atividades metacognitivas que servem para que o sujeito tome distância em relação aos conteúdos estudados e conscientize-se da sua maneira de aprender a aprender e do seu papel no êxito das suas aprendizagens (Hadji, 2001).

Para incentivá-los a participar desta nova maneira de registrar suas produções e acompanhar a sua construção do conhecimento, algumas leituras sobre o assunto, em textos complementares disponíveis na Internet, foram solicitadas, objetivando destacar o embasamento teórico da proposta e o conhecimento de outras vivências, o que, de certa forma, ajudou a dissipar um certo estranhamento por parte de alguns, que demonstravam não compreender o sentido da proposta. Esta atitude de estranhamento, em relação aos objetivos do portfólio, foi verificada em todos os semestres. Perrenoud (1996a) chama a atenção para o desafio de incorporar os alunos em uma nova forma de trabalhar e aprender, quando uma nova abordagem teórica-metodológica é introduzida, fazendo com que o ofício do aluno seja 
redefinido. Aponta para a necessidade de esclarecimentos sobre alguns fatores, como: implicação na tarefa, a transparência dos processos, ritmos, modos de agir e pensar, a mobilização do trabalho em grupo, a tenacidade em relação a tarefas que exijam maior investimento, a solidariedade. Todos estes aspectos são afirmados e relembrados, durante o semestre.

Por isso, as conversas sobre os conceitos teóricos presentes na proposta e a marcação de encontros específicos para que os alunos trouxessem, para a sala de aula, o material coletado a ser discutido em pequenos grupos e com o professor, auxiliaram a inclusão gradual dos alunos nesse novo fazer. De acordo com Schön (2000, p. 220, grifo do autor): "[...] a aprendizagem de um estudante é potencializada quando ele pode falar sobre as suas confusões, descrever elementos do que já sabe ou dizer o que já produz a partir do que o instrutor diz e mostra", delineando, então, um curso que alternou momentos individuais e coletivos, como ilustra a figura 1.

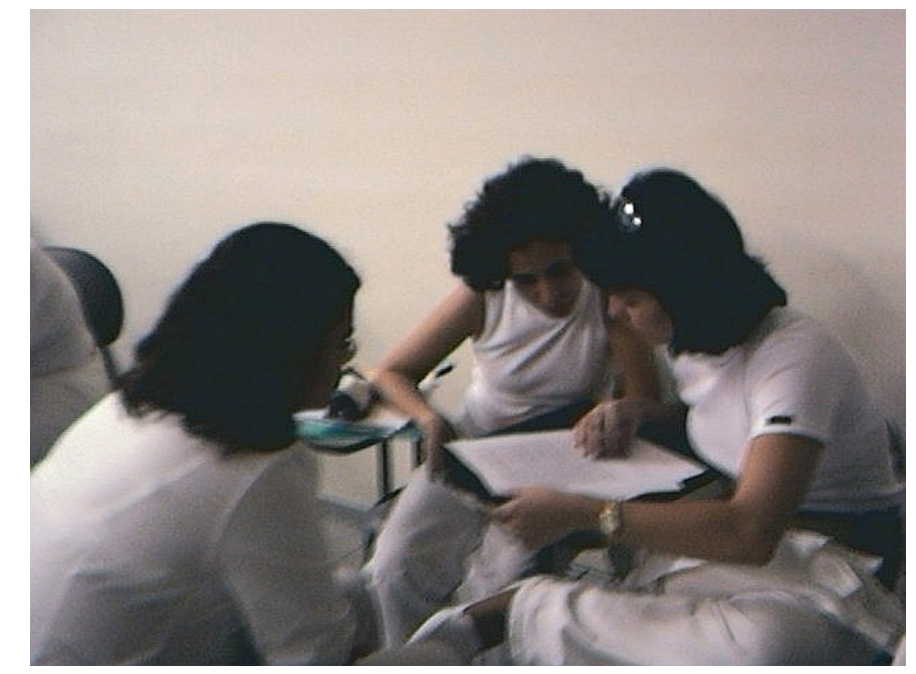

Figura 1 - Conversando com os colegas sobre as atividades do portfólio. Turma 2001.2

Nestes momentos, os alunos apresentaram as suas reflexões, impressões sobre a disciplina, opiniões, dificuldades, dúvidas ou qualquer outro material de interesse, pois: "Qualquer que seja a linguagem que venhamos a empregar, nossas descrições do ato de conhecer-na-ação são sempre 
construções" (Schön, 2000, p. 31), como mostra a figura 2, incluída no portfólio de um estudante.

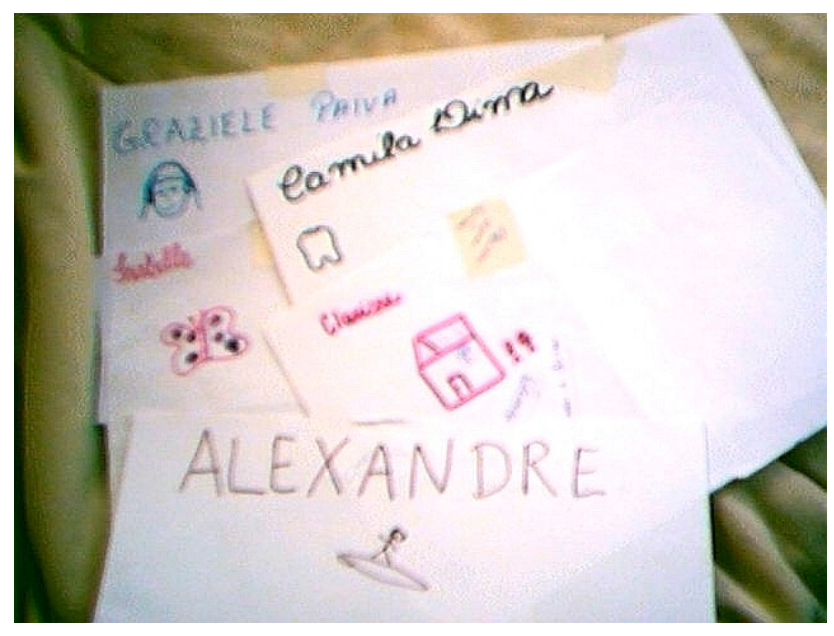

Figura 2 - Atividade incluída em portfólio de uma aluna

Embora, aqui, os detalhes de tal proposta não sejam aprofundados, esta atividade de apresentação fez parte do primeiro dia de aula, na turma 2001.1, intitulada: "Conhecendo o outro e deixando-se conhecer". Através de uma dinâmica, foi proposto que cada aluno se apresentasse aos colegas através de um desenho, introduzindo, além da oralidade, uma outra linguagem.

Esta atividade, assim como outras, ao ser selecionada e incluída no portfólio de aprendizagem ou demonstrativo, é submetida a uma organização pessoal que não excluiu a apresentação de uma capa, folha de rosto, sumário, além de uma conclusão final, como ilustra a figura 3, extraída do portfólio de aprendizagem da aluna P.R., da turma 2001.1. 


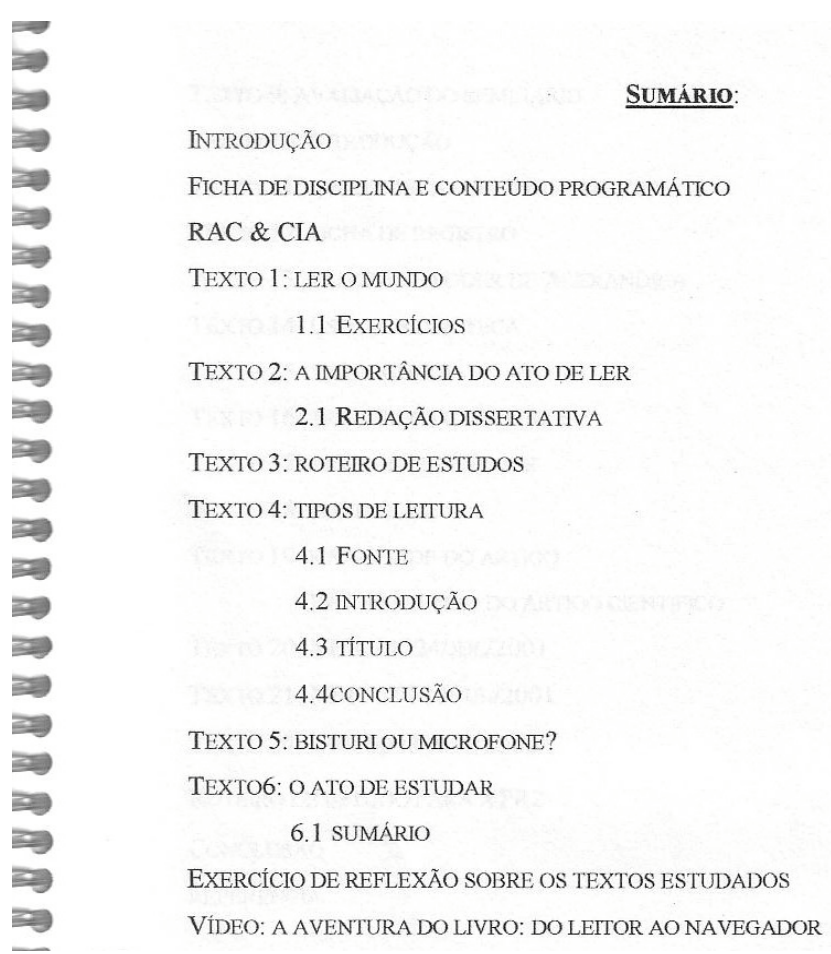

Figura 3 - Exemplo de sumário de um portfólio de aprendizagem

Outro exemplo é o registro, representativo da reflexão-em-ação (Schön, 2000), própria da avaliação formativa que, criticamente, leva o aluno a pensar sobre as dificuldades ou facilidades vividas durante o curso, possibilitando-lhe reestruturar suas estratégias de ação, a compreensão dos assuntos abordados, como aponta J.R., aluna da turma 2001.2: "O portfólio de aprendizagem tem me ajudado a classificar e organizar informações, consultando fontes bibliográficas, desenvolvendo a escrita [...]" ou a conclusão escrita por J.G. (turma 2003.1) em seu portfólio: 
Bom, ao fim desse trabalho posso concluir que o meu objetivo maior foi :onseguido. Apesar deste portifólio só exigir a coleção de quatro produções ninhas, me levou a reler todos os outros trabalhos que desenvolvi ao longo deste ıeriodo, para que só assim pudesse concluir quais deles seriam os mais ¿dequados para trabalhar neste portifólio. Nessa procura dos melhores trabalhos sntão reli e refleti sobre o processo de cada trabalho, o que me fez valorizar ainda nais uns deles quando comparados a outros, e reconhecer grandes erros em alguns trabalhos.

Acredito que este portifólio tenha sido muito produtivo para mim já que revi, э repensei sobre muitos trabalho que talvez não fossem mais ser lidos por mim, sude refletir sobre os conhecimentos adquiridos por mim e também sobre meus sbjetivos em cada trabalho e pude avaliar ainda o meu processo de desenvolvimento por este primeiro período. Ou seja, penso que este é um trabalho que deve ser refeito ao fim de todos os períodos.

Figura 4 - Depoimento de aluno sobre o portfólio

Todos estes exemplos são indicativos de que os alunos, aos poucos, foram percebendo e incorporando, no cotidiano, as contribuições deste tipo de trabalho para o desenvolvimento de habilidades e competências necessárias ao estudante de graduação. Além disso, as manifestações acerca das atividades realizadas e o permanente diálogo com o professor, através de um acompanhamento sistemático, seguido de comentários orais e escritos, pareceram fortalecer a autoconfiança e afastar a imagem do cumprir as tarefas para passar de ano, assim como descentralizar o julgamento sempre depositado na mão do professor sobre o que se faz na sala de aula. É importante salientar que os trabalhos não recebem notas, pois procura-se desvincular a produção da visão classificatória e meritocrática, instituída pela escola moderna (Esteban, 1999, 2001). A cultura da nota está impregnada no fazer do aluno e a expectativa de recebê-la tão logo os trabalhos sejam devolvidos ainda é um obstáculo a ser vencido.

Outro aspecto que merece atenção é o fato de que os alunos costumam apresentar o portfólio da aprendizagem, porém, a construção do 
portfólio demonstrativo parece oferecer maior dificuldade. Este fato, provavelmente, está atrelado à interpretação unívoca, advinda da figura do professor, a que os estudantes foram submetidos ao longo da escolaridade e, por isso mesmo, poucos conseguem colocar no papel, com espontaneidade e clareza, as suas dúvidas, certezas e surpresas vivenciadas durante o processo, porque, até então, a escola sempre selecionou o que pode e deve ser dito pelo aluno (Esteban, 1999).

É válido mencionar também que uma das dificuldades a ser considerada na proposta da avaliação com portfólio é a sobrecarga do professor. Desde a implantação desta proposta, a configuração das turmas em torno de 30 alunos demanda disponibilidade de tempo para um acompanhamento pari passu, pois, como aponta Hadji (2001), a avaliação, com intenção formativa, requer, necessariamente, um trabalho de interpretações das informações coletadas, o que, conseqüentemente, impõe lançar mão de um quadro referencial teórico que dê conta dos múltiplos aspectos - afetivos, cognitivos, sociais - que integram o processo de aprender. Sem dúvida, a proposta do uso do portfólio exige maior disponibilidade do professor e um constante estudo, em diferentes áreas do conhecimento.

\section{CONSIDERAÇÕES FINAIS}

Todo trabalho diferente daquele já estabelecido causa estranheza e dificuldades iniciais que, no caso desta experiência, ainda em andamento, precisam ser superadas. Abandonar o já conhecido, instituído pelo sistema tradicional de avaliação, provoca no professor inquietudes que fazem parte do seu ofício, comprometido com uma avaliação dialógica e transformadora e, no aluno, uma certa desconfiança quanto ao "resultado" dessa avaliação.

No início da experiência, a atuação foi mais diretiva junto ao primeiro grupo, de forma a garantir o cumprimento das etapas requeridas para a construção do portfólio e a compreensão, por parte dos alunos, da importância deste instrumento avaliativo, nunca antes experienciado. Não é possível ignorar, além disso, que a inclusão desta nova maneira de trabalhar a avaliação também constituiu-se um desafio para a autora e, portanto, "amarrar" a proposta era fundamental. A cada semestre e a cada turma assumida foi, e ainda é, necessário, rever pontos nebulosos e aprimorar outros, colocando em prática a idéia de Schön (2000) sobre o professor reflexivo, para atender a premissa fundamental da 
psicopedagogia que é a melhoria da relação do sujeito com a aprendizagem.

Ainda há alguns entraves a serem vencidos: o primeiro, referente a uma mudança da concepção de avaliação, centrada na quantificação que permeia o pensamento dos alunos e professores, de modo geral e o segundo, a inserção de outras disciplinas que possam compartilhar dessa prática. A adesão de outros professores, principalmente, dos períodos seguintes, é um aspecto fundamental para a continuidade da assunção de um novo lugar para a avaliação, no contexto acadêmico.

Ao propor a avaliação com portfólio, contempla-se um preceito básico que é a reflexão sobre o progresso do aluno, em função de seus próprios objetivos e desta forma, altera-se a visão tão impregnada, na academia, de um aluno passivo, que focaliza a sua atenção na reprodução do objeto mostrado pelo professor. Ao criar, criticar, contextualizar, questionar o conhecimento, o estudante está produzindo sentidos e reconhecendo-se como protagonista da sua ação de conhecer, o que, sem dúvida, ancora o processo de autoria de pensamento, elemento fundamental para o futuro profissional que a universidade está formando.

\section{REFERÊNCIAS BIBLIOGRÁFICAS}

ALVES, L.P. Portfólios como instrumento de avaliação dos processos de ensinagem. Disponível em: <http:/ / www.ensinofernandomota.hpg.ig.com. br/textos>. Acessado em: 13 ago. 2002.

BOSSA, N.A. A psicopedagogia no Brasil: contribuições a partir da prática. 2.ed. rev e aum. Porto Alegre: Artes Médicas Sul, 2000. 131p.

ESTEBAN, M.T. A avaliação no cotidiano escolar. In: . (org.). Avaliação: uma prática em busca de novos sentidos. Rio de Janeiro: DP\& A, 1999. p. 7- 28.

. O que sabe quem erra? Reflexões sobre a avaliação e fracasso escolar.

Rio de Janeiro: DP\& A, 2001. 198p.

FERNÁNDEZ, A. O saber em jogo: a psicopedagogia propiciando autorias de pensamento. Porto Alegre: Artmed, 2001. 179 p. 
GARDNER, H. Inteligências múltiplas: a teoria na prática. Porto Alegre: Artmed, 2000.

HADJI, C. A avaliação desmistificada. Porto Alegre: Artmed, 2001. 136p.

PERRENOUD, P. Não mexam na minha avaliação! Para uma abordagem sistêmica da mudança pedagógica. In: ESTRELA, A.; NÓVOA, A. (org.). Avaliações em educação: novas perspectivas. Porto: Porto Ed., 1999. p. 171190. 1999b. 90 p.

Construir competências desde a escola. Porto Alegre: Artes Médicas,

SCHÖN, A.D. Educando o profissional reflexivo: um novo design para o ensino e a aprendizagem. Porto Alegre: Artmed, 2000. 256p.

SHORES, E.; GRACE, C. Manual de portfólio: um guia passo a passo para o professor. Porto Alegre: Artmed, 2001. 160p.

UNIVERSIDADE ESTÁCIO DE SÁ. Manual de Orientação Projeto Pedagógico - Curso de Odontologia. Rio de Janeiro: Universidade Estácio de Sá, 2002.

VILLAS BOAS, B.M. de F. Contribuições de porta-fólios para a organização do trabalho pedagógico. Estudos em Avaliação Educacional. São Paulo, n. 23, p. 137-152, jan./jun. 2001.

VYGOTSKY, L.S. Pensamento e linguagem. São Paulo: Martins Fontes, 1993. $135 \mathrm{p}$.

Recebido em: junho 2003 Aprovado para publicação: agosto 2003 